\title{
O PROGRAMA ESPECIAL DE TREINAMENTO NA FORMAÇÃO DO PROFISSIONAL DE ENFERMAGEM DO NOVO MILÊNIO: RELATO DE EXPERIÊNCIA
}

José Fernando Petrilli Filho ${ }^{1}$

Danielle Cristine Martins ${ }^{1}$

Petrilli-Filho JF, Martins DC. O programa especial de treinamento na formação do profissional de enfermagem do novo milênio: relato de experiência. Rev Latino-am Enfermagem 2001 julho; 9(4):91-3.

\section{INTRODUÇÃO}

Atualmente, vivemos em um mundo globalizado, sem fronteiras, onde o acesso à informação é aparentemente universal, a tecnologia é endeusada, transformações estão ocorrendo no modo de produção e por conseqüência o profissional do novo milênio terá que se ajustar a esta nova realidade ${ }^{(1)}$.

Assim, será mais importante a sua capacidade enquanto ser humano, ou seja, a criatividade, versatilidade, flexibilidade, capacidade de relacionar-se, comunicar-se, resolver problemas, do que apenas a formação profissional oferecida pelas Universidades, pois neste mercado competitivo a regra número um será estar no topo do ranking da excelência, onde será mais importante o "saberser" à "saber-fazer"

Neste contexto se insere o enfermeiro do novo milênio, 0 qual deverá tomar decisões complexas, adaptar-se a novas situações e atualizar constantemente seus conhecimentos ${ }^{(2)}$.

Todo este panorama do profissional do século XXI já era previsto na década de 70, quando o Professor Cláudio de Moura Castro, ex-diretor geral da Coordenadoria de Aperfeiçoamento de Pessoal de Ensino Superior (CAPES), baseado nas experiências da Faculdade de Ciências Econômicas (FACE) da Universidade Federal de Minas Gerais (UFMG) e nos Honors Programs das universidades americanas, idealizou o Programa Especial de Treinamento (PET), 0 qual visa uma formação global do aluno, o que infelizmente não ocorre na graduação devido à falta de espaço na grade curricular.

O PET consiste em um programa abrangente, pois ao longo de sua permanência no grupo os bolsistas se envolvem em atividades de ensino, pesquisa e extensão. Assim, o presente estudo tem como objetivo apresentar as finalidades, atividades do PET e tecer considerações sobre a importância desse programa para o profissional do novo milênio.

\section{O PROGRAMA ESPECIAL DE TREINAMENTO}

O PET tem como objetivo financiar alunos com potencial, estimulando e propiciando a estes participação em atividades extracurriculares, de modo a favorecer ao acadêmico a integração no mercado profissional e o desenvolvimento de estudo em programas de pós-graduação, preparando um profissional que no futuro atuará de forma global no mercado de trabalho, transformando e lutando pelos interesses profissionais de sua classe ${ }^{(3)}$.

A concepção do programa está baseada nos moldes de grupos tutoriais de aprendizagem e orientado pelo objetivo de formar globalmente o aluno. 0 tutor deve ter, no mínimo, a titulação de doutor, pertencer ao quadro permanente da universidade em regime de tempo integral, comprometer-se a dedicar uma carga horária semanal mínima de oito horas às atividades do grupo, comprometer-se à assumir a tutoria por um prazo mínimo de três anos e adequar-se a um perfil que inclua: vida acadêmica destacada; experiência na orientação de alunos; visão ampliada do curso de graduação; desenvolvimento das atividades ligadas à melhoria da qualidade de ensino do curso; bom relacionamento com os corpos docente e discente e identificação com a filosofia e os objetivos do PET.

Os grupos PET são formados gradualmente, pela seleção anual de bolsistas. A implantação e implementação dos grupos pressupõe a inclusão de alunos em diferentes estágios de andamento do curso, que deverão trabalhar de forma integrada. Para se candidatar é necessário apresentar rendimento acadêmico satisfatório, comprovado através do histórico escolar, não podendo haver reprovações em disciplinas do curso; comprometer-se a dedicar às atividades do programa um mínimo de doze horas semanais; não estar recebendo outro tipo de bolsa (de outra instituição de incentivo

\footnotetext{
${ }^{1}$ Acadêmicos do $8^{\circ}$ semestre de graduação da Escola de Enfermagem de Ribeirão Preto da Universidade de São Paulo, bolsistas do PET/EERP-USP; Orientadora: Cristina Maria Galvão, Professor Doutor da Escola de Enfermagem de Ribeirão Preto da Universidade de São Paulo, Centro Colaborador da OMS para o desenvolvimento da pesquisa em enfermagem, e-mail: crisgalv@eerp.usp.br
} 
à pesquisa), ser brasileiro nato ou naturalizado; não ter mais de vinte e dois anos na época de início da bolsa e estar regularmente matriculado no terceiro semestre do curso de graduação.

O PET tem como objetivos:

- oferecer uma formação acadêmica de excelente nível, visando a formação de um profissional crítico e atuante, através da facilitação do domínio dos processos e métodos gerais e específicos da investigação, análise e atuação da área de conhecimento; envolvimento dos bolsistas em tarefas e atividades que propiciem 0 aprender fazendo; discussões de temas éticos, sócio-políticos, científicos e culturais para o país e/ou para o exercício profissional. - promover a integração da formação acadêmica com a futura atividade profissional, especialmente no caso da carreira universitária, através da interação entre as atividades de ensino, pesquisa e extensão.

- estimular a melhoria do ensino de graduação através do desenvolvimento de novas práticas e experiências pedagógicas; atuação dos bolsistas como agentes multiplicadores; interação dos bolsistas com os corpos docente e discente da instituição e participação em atividades características de programas de pósgraduação ${ }^{(3)}$.

\section{A ESCOLA DE ENFERMAGEM DE RIBEIRÃO PRETO E O PROGRAMA ESPECIAL DE TREINAMENTO}

A Escola de Enfermagem de Ribeirão Preto (EERP) foi fundada em 1953 por Glete de Alcântara, a qual era formada em enfermagem pela Escola de Enfermagem de Toronto (Canadá) na década de 40. No ano de 1963, Glete de Alcântara exercia o cargo de professora e diretora da EERP, sendo que nesse período recebeu o título de Professora Catedrática, o primeiro da América Latina.

Já em 1975, a unidade iniciou seu programa de pósgraduação e em 1988 passa a ser considerada Centro Colaborador da Organização Mundial da Saúde. Atualmente, mantém Curso de Graduação, Cursos de Pós-Graduação (três em nível de mestrado e quatro em nível de doutorado) e outros cursos. OPET originou-se na EERP no ano de 1988, tendo passado por este 3 tutores e 57 bolsistas. O grupo PET/EERP, atualmente, é composto por onze bolsistas, dois suplentes e dois voluntários, totalizando quinze estudantes de graduação, um tutor e cinco professores colaboradores.

Dentre as atividades realizadas pelo programa destacamos: reuniões semanais dos integrantes do grupo juntamente com o tutor e professores colaboradores, para planejamento de atividades e discussões de temas; seminários científicos quinzenais para que os bolsistas e outros alunos da graduação possam divulgar seus trabalhos científicos na unidade; painel, onde os bolsistas expõem para a unidade assuntos que estão em foco em nível nacional e mundial; produção de trabalhos científicos dentro da área de interesse do bolsista; curso de uma língua estrangeira; estímulo e incentivo a participação em eventos culturais e científicos para aquisição de novos conhecimentos e divulgação da produção individual; organização de uma mostra cultural, científica e artística anualmente, além de palestras e cursos de atualização durante 0 ano para estudantes da área da saúde; leitura obrigatória de dois livros anualmente, para discussão em grupo; estímulo para a realização de estágio extracurricular nas férias.

0 ingresso neste programa como bolsistas tem nos permitido um grande e importante crescimento pessoal e profissional. O PET nos ensinou como conviver em grupo, discutindo, respeitando e construindo com o outro, e tem nos demonstrado que a contribuição de cada um dos membros com as suas diferenças, a inter-relação entre as pessoas e, primordialmente, o estilo de liderança adotado pela tutoria, são fatores que refletem a formação e o funcionamento do grupo. 0 trabalho em grupo, bem como o exercício da atividade de liderança, estão ligados diretamente à enfermagem, visto que 0 enfermeiro desenvolve o seu trabalho em grupo, e através da liderança busca o aprimoramento da prática profissional e principalmente 0 alcance de uma assistência adequada e de qualidade, conciliando os objetivos organizacionais com os da equipe de enfermagem.

Também tem nos ensinado a descobrir novas aptidões, estimulado nossa criatividade, bem como o interesse pela cultura, política, conhecimentos gerais e específicos e de língua estrangeira. Através desse programa estamos tendo a oportunidade de nos engajar e descobrir uma parte do mundo da pesquisa, indispensável a qualquer profissional que não deseja entrar de forma rotineira no cotidiano de suas atividades.

Não poderíamos deixar de acrescentar que o PET tem nos incentivado muito no sentido de termos uma visão mais crítica, a não nos contentarmos com a "mesmice" das coisas, mas a buscarmos sempre mais. Podemos afirmar que a experiência como integrantes do PET nos trouxe uma nova visão da enfermagem e do mundo, possibilitando o nosso ajuste às características exigidas ao profissional do novo milênio.

\section{CONSIDERAÇÕES FINAIS}

Frente ao exposto, entendemos que o PET é de suma importância na formação do profissional do novo milênio, visto que os objetivos desse programa buscam oferecer uma formação acadêmica de excelente nível aos alunos de graduação; incentivar 0 
ingresso na pós-graduação; estimular a melhoria da qualidade de ensino de graduação através do desenvolvimento de novas práticas e experiências pedagógicas; multiplicar as atividades desenvolvidas pelos bolsistas sobre o conjunto de alunos do curso, e a interação dos alunos do programa com o corpo docente e discente da instituição.

\section{REFERÊNCIAS BIBLIOGRÁFICAS}

1. Sordi MRL, Bargnato MHS. Subsídios para uma formação profissional crítico-reflexivo na área da saúde: desafio da virada do século. Rev Latino-am Enfermagem 1998 abril; 6(2): 83-8.
Com a grande competitividade do mercado de trabalho exigindo profissionais generalistas-especialistas, 0 alto investimento em alunos com potenciais reverterá em benefícios para a profissão $e$ conseqüentemente para a população em geral, através de uma assistência de qualidade.

2. Alfavaro-Lefevre R. Pensamento crítico em enfermagem: um enfoque prático. Porto Alegre (RS): Artes Médicas; 1996.

3. Cassiani SHB, Ricci WZ, Souza CR. A experiência do programa especial de treinamento na educação de estudantes de graduação em enfermagem. Rev Latino-am Enfermagem 1998 janeiro; 6(1):639. 